\title{
Unidad y pluralidad de la filosofía*
}

\author{
Juliana González
}

no de los rasgos más patentes y significativos de la filosofía es el de su diversidad y de la complejidad de sus funciones. Esto dificulta, obviamente, el poder ofrecer una "definición" de ella que pueda ser válida para todas y cada una de las distintas ideas de la filosofia que se han producido en la historia, y que incluso llegan a coexistir en un mismo momento histórico, como ocurre en el presente. El problema de la unidad y diversidad de la filosofia es ciertamente uno de los problemas básicos de la propia filosofía; pero éste, en nuestro siglo, ha tenido particular importanci ${ }^{1}$, y la sigue teniendo hasta hoy en que perdura como problema abierto para la reflexión filosófica.

¿Cómo responder a la pregunta de qué es filosofía sin diluir el dato de la diversidad? ¿A qué se debe ésta? ¿Qué es aquello que distingue lo que es filosofía de lo que no lo es? ¿Qué tienen en común las distintas filosofias? ¿Y cómo reconocer la pluralidad y relatividad, y, al mismo tiempo, tener razones para optar por una posición filosófica?

Esta pluralidad la hemos vivido de manera muy sensible en nuestra comunidad, particularmente dentro de esta Facultad, en la cual han coexistido siempre las más diversas corrientes y posiciones filosóficas. El estudiante de filosofía tiene que ponerse a sí mismo a prueba en esta diversidad, asumirla, hacer aprendizaje de ella para poder decidir por cuenta propia cuál es la posición que le resulta más convincente.

Pero además, a una misma generación nos ha tocado presenciar, dentro de esta Facultad, gran parte de dicha diversidad y de los cambios que ha sufrido la filosofía del siglo; el auge y la caída de varias corrientes

Conferencia dictada en la Facultad de Filosofía y Letras de la Lnam en enero de 1992.

No en vano la polémica entre historicismos y "antihistoricismos" que ha estado tan presente en el filosofar contemporáneo. 
predominantes. Personalmente, asistí a las últimas expresiones de una poderosa influencia de la metafísica tomista; luego a la hegemonía y al desvanecimiento del neokantismo; también presencié el auge del historicismo y del existencialismo, en sus líneas heideggeriana y sartreana. Asimismo, he vivido de cerca la crítica a estas corrientes filosóficas y los intentos por reinstaurar la metafísica desde nuevas perspectivas teóricas y metodológicas. He visto el desarrollo de la filosofia latinoamericana y el auge de los distintos marxismos que han prevalecido aquí, y en especial las discrepancias y polémicas entre el marxismo humanista y el estructuralista, así como el marcado contraste que ofrecen la concepción marxista y la concepción "analítica" de la filosofía, cada una de las cuales, a șu vez, ha sufrido significativos cambios. Estamos siendo testigos, en fin, de las crisis, las aporías y las nuevas búsquedas de la filosofia hoy, incluyendo el impasse de la llamada "posmodernidad".

La filosofía del presente - hemos afirmado en otra ocasión- ha estado "en el centro mismo de los principales acontecimientos del siglo: ha sido participe de sus grandezas y sus miserias, de su racionalismo y su irracionalidad, de su saber de la vida y no se diga de la muerte, de la destrucción y la guerra. Ha estado comprometida en revoluciones de toda indole, teórica y práctica, científica y artística, política, moral y social. Se ha revolucionado a sí misma y ha sido protagonista activa del proceso. Ha compartido, en fin, las ilusiones y desilusiones de nuestro tiempo, sus conflictos y sus fracasos, sus crisis y sus esperanzas".

Pero ciertamente la pluralidad de la filosofia no es exclusiva del presente; se ha dado en toda su historia, desde los comienzos de la filosofía occidental en Grecia. Ya el proceso histórico de la filosofía griega muestra un recorrido teórico múltiple y diverso en el cual se hace claramente expresa la riqueza de posibilidades del filosofar. Los filósofos griegos, en efecto, abrieron los caminos y los horizontes de la concepción de la filosofía como "filosofía primera", llamada después "metafísica"; pero también, cabe decir, que se dieron en Grecia las primeras concepciones "anti-metafisicas". Se abrieron asimismo los caminos de la ética y también los de la sofística, la cual, a la vez, se desarrolló en sus vertientes pedagógicas y políticas, así como en las lógicas, retóricas y lingüísticas. La filosofia griega se plasmó dentro de grandes creaciones teóricas, abstractas y sistemáticas, pero también en las formas de filosofía práctica, concreta -concebida, incluso, para resolver el destino moral de sus cultivadores. La filosofía griega exaltó sin duda los fines teóricos, científicos y racionales

\footnotetext{
2 Juliana González, Las filosofías del siglo xx. Toluca, en Dos Valles, vol. I/núm. 1, eneromarzo, 1988.
} 
del filosofar, exaltó el logos, la razón y la palabra; pero también, en Grecia, la propia filosofía generó la crítica del logos y dio nacimiento a la primera modalidad del escepticismo filosófico que propuso la suspensión del juicio (epojê) y el silencio o el mutismo (afasia).

Parecería como si las diversas potencialidades del filosofar, con sus alternativas y variantes, hubieran sido ya exploradas, incluso con plenitud, en la creación griega; como si se hubiese recorrido un cierto "ciclo" y "circuito" básico, o un repertorio originario de variantes y opciones posibles, que la filosofía posterior habría de recorrer una y otra vez, aunque no $\sin$ introducir otras opciones y siempre en forma nueva y desde estadios y niveles diferentes, a la manera de la espiral hegeliana (aunque, desde luego, dentro de un movimiento transformador que no tiene en la realidad histórica la rigidez esquemática, predeterminada y absolutista en que pensaba Hegel).

\section{米米}

¿Y cómo valorar la pluralidad? ¿Es signo de alguna falla o deficiencia? ¿Cómo dar razón de la diversidad y a la vez encontrar aquello que es común a las distintas filosofias?

No parece ciertamente posible -y quizá tampoco deseable- alcanzar una definición única, uniforme y definitiva (que resultaría por necesidad abstracta y estática) de la filosofia; pero si podemos tener acceso a algunos rasgos inberentes a la filosofía en general, a algunas propiedades esenciales de ella que están, de un modo u otro, presentes en la tradición occidental, desde sus origenes en la filosofía griega. Se trataría de las notas distintivas con que se configuró inicialmente el pensar filosófico y que perduran a través del tiempo (dando continuidad y cohesión a todo el proceso histórico, revelando lo que tienen básicamente en común las diversas filosofías). Son factores constantes dentro de variables. Ellos permiten, no solamente exhibir la unidad esencial del filosofar, sino comprender la diversidad misma, mostrar su razón de ser e incluso su propia virtud.

\section{米米}

Desde su nacimiento en Grecia, la filosofia exhibió precisamente una de sus características más propias: la conciencia de sí misma, el saber que ella implicaba el inicio de una actividad nueva que se iba configurando con características propias; éstas se referían, primeramente, al filósofo mismo, a la nueva e intensa experiencia humana que expresaba el filosofar, a sus 
propósitos y sus objetivos o fines propios. ${ }^{3}$ Así se fueron delineando una serie de rasgos que trazan el perfil del sujeto del filosofar, del filósofo como un hombre suigeneris que realiza una actividad suigeneris.

La filosofía, como es sabido, nace de una fuente de experiencia humana, que los griegos llamaron thauma y que cabe traducir por "asombro", "admiración", capacidad de "maravilla". El filósofo, en efecto, se dispone ante la realidad en actitud de incógnita, de perplejidad, de verdadero azoro, recobrando la inocencia de la infancia y la capacidad de preguntar. $Y$ es esta capacidad de asombro y pregunta lo que hace de la filosofia una "vocación universal". En todo tiempo y lugar en que el hombre se asombra y se pregunta acerca del qué, del porqué y del para qué, se está haciendo de algún modo filosofía. La diferencia con el filósofo "profesional" es que éste hace de la espontánea capacidad de perplejidad e interrogación el oficio de su vida, al cual dedica, vocacionalmente, todo su empeño, haciendo del preguntar mismo y del indagar cuestión de método y de razón.

El asombro, la capacidad de maravillarse, en efecto, están en la raíz más originaria de la experiencia filosófica. Pero el asombro despierta a su vez toda otra serie de nuevas potencialidades. De Tales de Mileto se dirá que es el primer pbilo-sophós, además de ser uno de los siete sophoi o sabios griegos. ¿Qué indica esa philia que se añade a la sophia para dar lugar a una nueva vocación?

Todo parece indicar, como lo confirmará la filosofía posterior, que la esencia del filosofar está puesta, ciertamente, en esa philia, palabra que en su significación originaria remite a una vivencia radical que no se agota en los términos "amor", "amistad", "deseo", salvo que estos se recobren en su significado más amplio e intenso. El amor está, en efecto, para el griego, en la base del filosofar, de la búsqueda del saber, de la "pasión" por el conocimiento; Eros es motor del logos, como lo vio Platón.

Y en tanto que "amor", la philia por la sopbia consiste, además del asombro y la problematización siempre renovados, en un estado originario de búsqueda, indagación, investigación o zétesis. El filósofo será en esencia siempre "buscador" antes que "poseedor" del conocimiento: por eso es "amante". Aunque en realidad, ya la propia pregunta filosófica, el "problema" como tal, es forma de conocimiento, de "tener presente" (y "hacer presente") lo que suscita nuestra interrogación. Platón afirmaba que el que busca el conocimiento es aquél que "ya sabe" lo que busca y al mismo tiempo "no sabe", y por eso busca. $\mathrm{El}$ amor al saber se origina por tanto de un saber y no saber al mismo tiempo.

3 Cf. Eduardo Nicol, La idea del hombre. México, Stylo, 1946; Los principios de la ciencia. México, FCE, 1965, y El porvenir de la filosofía. México, FCF, 1972. 
La filosofia lleva incluso hasta sus últimas consecuencias la capacidad de interrogar o cuestionar. No sólo se pregunta qué es lo que existe. También pone en duda si existe realmente. Y no sólo se cuestiona la realidad, sino el saber mismo, los conocimientos, las ideas que se tienen acerca de todas las realidades. La filosofia tiene una fundamental función crítica - que deriva de esa experiencia originaria y básica de asombro, de interrogación y búsqueda. La capacidad de dudar suele ser precisamente el acto inicial, el arranque del filosofar, y en esta medida, la filosofía es lo contrario del dogma, de todo juicio acrítico y de toda pretensión de "ya saber" de manera definitiva.

Sin embargo, en tanto que amor por el saber, la filosofía es amor por la verdad, por un conocimiento cierto y radical. La filosofía lleva en su ser mismo la "duda" y paradójicamente también el afán de "certidumbre" (certeza "indubitable", "apodíctica", como la llamó Descartes). La filosofía nació también como "ciencia" o episteme - a la vez que la ciencia nació en Grecia como filosofía. Lo que en realidad se originaba con Tales de Mileto era una misma actividad de ciencia-filosofía. Y lo que la episteme significa básicamente es lo que también habrá de llamarse conocimiento objetivo; es un saber de las cosas "según su naturaleza", tal y como ellas son "en sí mismas y por sí mismas" —-según lo conceptúan los filósofos griegos. La filosofía es afán de conocimiento cierto y fundamental, definitivo y principal. Su propósito es la verdad, y la verdad fue incluso concebida por los griegos como saber absoluto o saber de lo absoluto.

Por eso también la filosofía es logos. Es logos como "palabra" o lenguaje, lo cual implica que el griego reconoció la esencial comunicabilidad del pensar filosófico; el logos de la filosofía es logos dialógico. La filosofía nació como diálogo y por tanto, como posibilidad de discrepancia o desacuerdo; de ahí también su carácter de búsqueda interminable y de pensamiento esencialmente crítico, sometido a un dar y pedir razones.

Asimismo, la filosofia es logos precisamente porque hace de "la razón", de la inteligencia humana, el instrumento de acceso a la verdad, al misterio de lo que las cosas son. Es el medio que permite desentrañar en éstas lo que, a su vez, es su propio logos interno, su "Ley" o racionalidad, la cual, para los griegos, está presente en la totalidad de lo que existe. ${ }^{4}$

Y por esto, además, la filosofía es theoria, en el sentido de "visión" desinteresada, que tiene su fin en sí misma. El desinterés coincide, por un lado, con la pbilía o el amor y, por el otro, con su propia objetividad o verdad, la cual se concibe como un fin suficiente en sí mismo.

4 Logos, en efecto, tuvo estos tres principales sentidos: "palabra", "razón", "ley" 
La filosofía es ciertamente pasión por la verdad, es voluntad de verdad, y la verdad implica un estado que afecta simultáneamente al "sujeto" y al "objeto" del conocimiento; la verdad (alétheia) remite a un literal "quitar velos", tanto del mundo como del hombre; en este sentido, la verdad es el "encuentro" que se produce entre ambos, por el cual el mundo es des-cubierto y el hombre se "des-vela" o se "despierta" ante la realidad. Y la verdad es, asimismo, encuentro, en el sentido del hallazgo correlativo a la búsqueda, a la pbilía.

Pero entonces se hace patente lo que sería una especie 'de "esencia contradictoria" del filosofar (que corresponde a la esencia contradictoria del amor): la philia por la sophia es búsqueda y a la vez encuentro, pregunta y respuesta. Es, en definitiva, carencia y plenitud, vacío y lleno, como lo es el eros platónico. La intensidad de la certidumbre filosófica es proporcional a la intensidad del amor o del deseo por la verdad. Ésta es la paradoja del amor y del deseo: el amante busca poseer y sólo mantiene su amor en su desposesión; la medida de su vacío es la de la plenitud de lo deseado.

Pudiera desprenderse así que hay una especie de tensión entre búsqueda y encuentro, entre afán y logro, entre duda y certidumbre, que se halla, ciertamente, en el corazón mismo de la filosofía; ésta lleva en sí su propia dualidad, sus propias posibilidades contrarias. Lo cual pudiera constituir una de sus características esenciales, que revela uno de los factores fundamentales y decisivos de su intrínseco movimiento, de su necesario devenir y de su diversificación y pluralidad. Así se explica que haya momentos del filosofar, o que haya filósofos, que hagan énfasis en el aspecto crítico y dubitativo, otros, en cambio, que ofrezcan las grandes respuestas teóricas y sistemáticas.

\section{潘棌}

Esto por cuanto al "sujeto" de la filosofía. Pero también de su "objeto" derivan otra doble posibilidad y otra tensión inherentes a la esencia del filosofar. ¿De qué se ocupa la filosofia? ¿Cuál es su objeto de estudio? ¿Cuál es su campo o territorio propio?

Si recaemos nuevamente en la primera formación histórica que tuvo la filosofía de Grecia, nos encontramos con las tres etapas principales en la determinación de su objeto:

Primero, en el período presocrático, como se sabe, la filosofía recayó en la "naturaleza" (physis) tomada como la unidad de "todo" lo existente. El objeto de la filosofía en este primer momento fue ese todo tomado precisamente por cuanto a su "naturaleza" primordial, a su "origen y fundamento", que es lo que da unidad y eternidad a la realidad. 
Pero después, en el período socrático se produce un significativo viraje en el objeto de interés de la filosofía: éste no será ya la "naturaleza" sino el "hombre", visto en su interior, y en aquello que tiene de diferente respecto de la naturaleza no humana. A este viraje se le ha llamado "giro antropocéntrico", llevado a cabo por los sofistas y Sócrates. Surge la filosofía como forma de autoconciencia del sujeto del filosofar y lo que busca ahora, en particular con Sócrates, es al mismo tiempo que conocer la verdad del hombre y los fines de la vida humana, actuar en concordancia con estos fines. A partir de Sócrates, la dimensión antropológica y ética quedó incorporada al objeto de la filosofía.

Pero inmediatamente después, con Platón y Aristóteles, la filosofía no sólo recupera las preocupaciones previas acerca de la realidad en general, del ser y del devenir que se habían originado en el período presocrático, sino que amplía y completa sus campos de atención mostrando que ella se despliega en las más diversas direcciones, exhibiendo así toda la riqueza y complejidad, tanto de su objeto como de sus objetivos y de sus distintas funciones.

De estas variantes derivan, por un lado, el problema del carácter teórico o práctico o teórico-práctico de la filosofía y, por el otro, el de las diversas "ramas" de ésta.

La filosofía - hemos dicho- nació como episteme o ciencia, cuyos fines propios son esencialmente teóricos o cognoscitivos. La filosofíaciencia (episteme) se había originado desde la sabiduria (sophia) prefilosófica, dejando atrás los fines prácticos de dicha sapiencia. Pero sobre todo a partir del momento socrático, la filosofía se constituye como una nueva forma de sabiduria o de sapiencia con fines prácticos (éticos y éticopolíticos) bien definidos.

Y en tanto que sabiduría o sophia, la filosofía no es el saber abstracto, teórico, meramente intelectual, que caracteriza a la ciencia, sino un saber vital, un saber práctico que repercute en la existencia concreta de los seres humanos. La filosofía se pone al servicio de la vida: es una manera de vivir. La verdad y el logos se tornan, para el filósofo, base de la vida individual y de la vida colectiva. El saber, el conocimiento objetivo o fundado se convierte en el fundamento de la acción, generándose así una nueva forma de praxis o de acción.

Para algunos filósofos, incluso, desde los tiempos griegos hasta el presente, esta función vital o existencial es la función propia de la filosofia. Éste es el caso, por ejemplo, de Kierkegaard, para quien la verdad filosófica no ha de ser algo vacío e "inhabitable", sino "algo por lo cual vivir o morir"

¿Cómo definir entonces la filosofía? ¿Como teoría, como praxis, como ambas formas, fundidas a la manera paradigmática de la sintesis platónica? 
De esta doble función del filosofar se engendra, en efecto, otra doble posibilidad, otra tensión, a veces resuelta en armonía, otras veces abierta en posiciones polémicas, dando lugar a variedades y variaciones esenciales en la manera de concebir los fines propios de la filosofía. Aquí se encuentra otro foco de diversidad que explica su pluralización, la cual deriva precisamente de esta doble posibilidad suya: de "ciencia" y de "sapiencia", de teoria y de praxis.

Y por otro lado, de la multiplicidad de objetos posibles derivan precisamente las distintas "ramas de la filosofia", o disciplinas filosóficas, que en la época griega incluian también muchas de las ciencias particulares que posteriormente se independizaron de ella. Así, la filosofía se concibe como metafísica o "filosofía primera", según la llamó en realidad Aristóteles, y cuyo objeto es el ser y a la vez el conocimiento. Como ética o ética-política, como lógica, como física, biología, matemática, como poética, psicología, etcétera.

La filosofia, en efecto, puede volcarse hacia distintos sectores o aspectos de la realidad y la cultura, y cada uno convertirse en su "objeto". Lo que la define, desde este punto de vista, no es, entonces, la posesión de un objeto propio y específico, sino "la manera" de ocuparse de cualquier objeto; su método de estudio, el nivel desde el cual enfoca al objeto, la generalidad y radicalidad, en sintesis, con que éste es visto.

Pues, en efecto, aunque se trate de sectores particulares, lo propiamente filosófico es la búsqueda de lo general, de lo fundamental y de lo "esencial"; de aquello que proporciona razones últimas o las más decisivas y significativas de las cosas. Busca la verdad radical aunque ésta se conciba como la ausencia de verdad; busca el fundamento, aunque éste en ocasiones se piense paradójicamente como el no-fundamento.

\section{***}

En resumen, serian notas distintivas de la filosofia, las siguientes:

1. La esencia problematizadora y critica del filosofar, tn la cual se puede sintetizar todo ese complejo de funciones cifradas en el asombro, el amor al saber, la búsqueda, la interrogación, la duda, que definen la actitud fundamental del filósofo.

2. La naturaleza dialógica del logos filosófico, de la cual deriva la comunicabilidad de éste y también las posibilidades de discrepancia y desacuerdo que son intrínsecas a la filosofia.

3. El propósito racional, teórico y científico de la filosofía; la filosofía es "ciencia rigurosa" en el sentido originario de la episteme, que quiere decir conocimiento objetivo, racional, metódico, sistemáti- 
co y teórico, el cual la filosofía realiza con su propio rigor y sus propios métodos de conocimiento y de pensamiento.

4. La función práctica de la filosofia. La filosofía es forma de sopbia o sabiduria. Principalmente se trata de una función ético-política, en el sentido más amplio de estos términos.

5. La universalidad, la radicalidady la esencialidad del conocimiento filosófico, ya tenga éste por objeto la totalidad, ya regiones particulares del ser y del conocimiento.

Pero estos rasgos esenciales no se realizan por igual en las distintas filosofías. Ello explica - al menos en parte- su notable diversidad. Los cambios se deben, ciertamente, a la propia naturaleza crítica y dialógica del filosofar, y a la pluralidad de objetos de la filosofía. Pero se deben también, particularmente, al hecho de que algunas de sus funciones son contrarias y no siempre armonizan entre sí; esto da lugar a las marcadas diferencias y contrastes que existen entre las filosofias. ${ }^{5}$

Hay así grandes creaciones filosóficas cuya esencia está precisamente en su capacidad de realizar todas estas distintas posibilidades y hacerlas, no opuestas, sino complementarias. El caso más notable quizá de todos los tiempos sigue siendo Platón. Su filosofía se caracteriza precisamente por su capacidad de reunir ciencia y sapiencia, teoría y praxis, pensamiento y vida; por conjuntar, de manera excepcional, la razón, el mito, el arte, la acción. Y se caracteriza asimismo por ser una filosofía que está siempre en movimiento: ella parte siempre, consciente y expresamente, del estado de asombro y de pregunta; hace incluso de la pregunta y la búsqueda el motor del filosofar. Platón ciertamente busca, y encuentra, y vuelve a buscar y en este proceso se mantiene hasta el final. Por esta razón, entre otras, se ha dicho que "Platón es la filosofía y la filosofía es Platón". Lo es, precisamente por reunir en su creación el dinamismo y la peculiar riqueza de posibilidades intelectuales y vitales que permite realizar la filosofia.

Pero no toda filosofia abarca en sí misma tal dinamismo y tal multiplicidad. En el despliegue histórico de la filosofía occidental suele producirse, como se ha dicho, una cierta alternancia entre las filosofias que buscan conjuntar y armonizar los distintos aspectos del todo filosófico, y las filosofias que se definen en una u otra posibilidad, oscilando, en última instancia, entre la ciencia y la sapiencia, entre los momentos constructivos de la filosofía y sus momentos des-constructivos y críticos.

'Es desde luego evidente que el cambio responde asimismo a las transformaciones históricas generales por las que atraviesa la humanidad. La filosofia es, sin duda, expresión de su tiempo. Aqui se intenta solamente destacar las otras razones de la pluralidad y el devenir de la filosofia que obedecen a su propia dinámica interna. 
Se dan así aquellas filosofias que defienden con exclusividad su carácter científico, racional y teórico. O por el contrario, las que ponen todo en su significación vital o existencial, aunque con ello se renuncie a los rigores de la ciencia y de la lógica, defendiendo lo concreto y lo práctico, lo emocional e individual, lo que no se presta a quedar envuelto ni paralizado en ningún "sistema". Se dan aquellas filosofias que se definen por ser grandes construcciones sistemáticas, y buscan dar respuestas universales y fundamentales, asentadas en firmes certidumbres y convicciones, en contraste con las filosofias predominantemente dubitativas y críticas, cuya función primordial es abrir la interrogación destruyendo las falsas ilusiones y las falsas seguridades, posibilitando muchas veces con ello, no sólo la veracidad, sino la aparición de nuevas fuerzas liberadoras y creadoras. La filosofia es indudablemente uno de los grandes instrumentos de la racionalidad humana, es creadora de las cosmovisiones más universales y más racionales. Pero la filosofía es también la que ha producido y produce las más profundas y devastadoras críticas a la razón y a todas las pretensiones de los absolutismos de la razón.

Son filósofos, así, figuras tan disímbolas como Parménides y Sócrates, Aristóteles y Diógenes, el cínico, san Agustín y Descartes, Pascal y Kant, Hegel y Bergson, Marx y Husserl, Nietzsche y Wittgenstein, Heidegger y Ayer, Simone de Beauvoir y Quine, Bertrand Russell y Foucault, Habermas y Davidson, por sólo citar algunos de los más conocidos, cuyas diferencias y contrastes son de significativa obviedad.

\section{粠粠}

Por otra parte, tampoco la variación y la diversidad de las filosofías son fortuitas, arbitrarias y caóticas. Por el contrario, hay articulaciones esenciales entre unas posiciones filosóficas y otras, ya sea a través del tiempo, ya en un mismo momento histórico. Entre todas cabe decir que se forma un tejido unitario, gestado por su misma diversidad y por su dinamismo. Cada tiempo histórico reclama unas respuestas, y no otras, cada voz filosófica posibilita el diálogo, abre nuevos horizontes, nuevos "claros del bosque" (como diría Heidegger) en la búsqueda inagotable del saber filosófico.

La bistoricidad forma parte de la naturaleza misma de la filosofia. Su pasado no es para ella algo aleatorio o simplemente complementario que se añada a su presente y a su proyección futura. No hay propiamente caducidad o "cancelación" en la historia de la filosofia; hay una peculiar vigencia y cierta perennidad de las creaciones filosóficas. Una de las razones de ello puede encontrarse, precisamente, en la significación que el problema tiene 
en filosofia, y su prioridad, incluso, respecto de las soluciones. Los problemas filosóficos, ciertamente, tienen una particular perdurabilidad y vigencia; ellos se rehacen, se replantean desde cada nueva situación, para transmitirse de nuevo hacia su fururo. Y acaso no sólo los problemas filosóficos tengan esa trascendencia histórica, sino que hay algo también en las respuestas mismas, en las verdades filosóficas que, por relativas que sean, tienen una peculiar capacidad de pervivir o de revivir en la historia. Esto explica el hecho de que aun filosofias muy lejanas en el tiempo puedan tener sentido para épocas y situaciones posteriores, e incluso que éstas las encuentren cargadas de significados vivos y fecundos. Los tiempos se interpenetran en realidad, interactúan, se afectan entre sí. Las filosofias van y vienen, por así decirlo; cada presente histórico acerca unas, aleja otras, en función de sus propias visiones y necesidades. Filósofos muy próximos en el tiempo pueden estar enormemente lejos de los intereses y de las preocupaciones del presente, pueden no decir nada ya, mientras que otros, muy lejanos, que incluso por una época permanecieron silentes, pueden cobrar nueva vigencia y trascendencia.

Quizás estos movimientos, estas interacciones en el tiempo no sean privativas de la historia de la filosofía sino del tiempo histórico en general (del tiempo humano), pero el hecho es que son claramente manifiestos en el devenir de la filosofia.

Cada presente filosófico, así, tiene una vinculación intrínseca con su pasado, rehace con él la conciencia del problema y la vivencia del asombro; atisba con él los horizontes abiertos y confirma o niega la validez de los caminos antes emprendidos. Pero al mismo tiempo, cada presente filosófico tiene que nacer de nuevo a la experiencia filosófica y plantearse por sí mismo sus interrogantes, como si fuese la primera vez; y tiene que respónder a éstas en su propio lenguaje y en ningún otro, dentro de sus propias categorías y sus propios parámetros mentales y existenciales, y no en otros; tiene que, en suma, encontrar sus respuestas dentro del contexto de su mundo, que es en el que se halla inmerso, y sólo de su mundo, siempre único, siempre nuevo e irrepetible.

La historicidad, asî, comprueba que la pluralidad no rompe la unidad, la cual conlleva en su propio núcleo la diversidad; ésta última no es, por tanto, un signo de deficiencia o de imperfección, sino de vida y movimiento: la pluralidad hace expresa la riqueza interna de la filosofia. Una de sus virtudes más propias es, en efecto, la no uniformidad, la no definitividad, el ser pensamiento abierto e inagotable.

Pero a la vez, tampoco esto significa que tengamos que desembocar en un mero eclecticismo, o que haya que mantenerse en una pura conciencia indiscriminada de la diversidad, sin poder optar por una forma 
de entender la filosofia, y sin tomar posición. Se trata en cada caso de ver qué enfoque podemos considerar más legítimo, más válido y más acorde con los problemas y las posibilidades teóricas y vitales de nuestra propia situación histórica - al mismo tiempo que se ha de mantener siempre despierta la conciencia de la pluralidad de los caminos filosóficos. Esto es: tener convicciones y a la vez permanecer abiertos al conocimiento crítico y al respeto de las otras posiciones, así como a la posibilidad de duda y autocrítica.

La idea de filosofia que, con esta conciencia, hemos hecho propia, es la idea que se aproxima a las concepciones que buscan abarcar unitariamente las diversas y "dobles" funciones del filosofar; que se concibe como búsqueda y a la vez como respuesta racional; la idea de filosofía como ciencia y sapiencia, como teoría y praxis. La filosofía no ha de perder, a nuestro juicio, sus propósitos de universalidad metafísica, atendiendo unitariamente al problema del ser, del devenir, del conocimiento, del ser del hombre y de los fines de la vida humana. Hay razones y bases profundas para afirmar que la visión de lo universal y de lo radical, propia de la "filosofía primera" se torna cada vez más necesaria en un mundo de excesiva especialización, de mera formalización y exterioridad como el nuestro. El presente necesita de visiones unitarias y esenciales, aunque no de visiones abstractas y totalitarias que no puedan dar cuenta a la vez de la diversidad y el devenir. Y necesita reconocer el valor de la razón, del método, del rigor científico, pero también admitir que la racionalidad no se agota en las formas de una pura razón univoca y formal. La filosofia no puede perder, ciertamente (sino a riesgo de perder su motivación originaria y esencial), la facultad de asombro y pregunta, y con ella la pasión de buscar, la voluntad de verdad, de penetrar en las raíces, de atravesar lo superfluo y querer llegar a lo fundamental o a lo esencial.

\section{**⿻丷木大}

Y podemos concluir así, que la filosofía "hoy" no es básicamente otra que la filosofia de siempre. Es plural como lo ha sido en su historia. Siguen presentes para ella, aunque a la manera de hoy (y no sin variaciones), las notas distintivas del filosofar: su visión crítica, su racionalidad, su misión formativa y humanística, su capacidad interrogante y dubitativa.

La filosofía hoy sigue siendo una actividad cardinal de la vida humana y sigue jugando un papel activo en las postrimerías del siglo y del milenio. Y así seguirá en la medida en que el tiempo prosiga, y perviva con él la posibilidad humana de vivir el asombro y de pasar la vida, socráticamente, interrogando en pos del saber; en la medida en que se trascienda 
la amenaza de un supuesto mundo "feliz", seguro y resuelto, donde ya no cabe preguntar. El destino de la filosofía es el destino del hombre y de su mundo.

Si hay opciones, si somos capaces de permitir que la tierra sobreviva, o sea, si somos capaces de sobrevivir, el filósofo seguirá construyéndose su espacio vital, que es el espacio para mirar, para escuchar y hablar: para dar y pedir razones; para hacer theoria filosófica, o sea, para ver de lejos y de cerca, a distancia y en profundidad, hacia lo hondo y hacia lo alto; el filósofo resguardará, como lo ha hecho hasta ahora, su espacio vital de silencio, que es aquél en el cual se gesta la reflexión, la vida interiorizada, fuente primordial de autenticidad y de capacidad de percepción.

Ciertamente, el filosofar tiende a apagarse en una hora dificil. El nuestro es tiempo de abismos, de confines, de situaciones límite, y de agotamiento. Pero también es tiempo de prodigios y promesas. Tiempo propicio para despertar el más intenso asombro ante el universo y ante nuestro saber de ese universo. Es tiempo que reclama intensamente el filosofar, que requiere de la penetración y de la amplitud del pensamiento filosófico, de las luces de una verdadera racionalidad, de la memoria de aquellos valores que son imperecederos y de aquellos ideales que son irreversibles; que proyecte hacia el futuro nuevas metas que den aliento y dirección a la vida humana. Es tiempo filosófico en el que se abren las más grandes interrogantes y en el que se requiere de aguda y profunda penetración para deshacer las falsas visiones e ilusiones, las nuevas fantasmagorías, los nuevos "opios" enajenantes que hunden la vida humana en la vacuidad de lo externo y lo inmediato.

Más allá de la densidad de una pura filosofía académica, o más bien, de la falsa academia que es rutina y mera escolaridad, está la posibilidad de que el amante del saber recobre su estado originario de asombro y de vigilia. Es tiempo, en fin, en el que el filosofar tiende a renacer con renovada necesidad, y en el que se requiere precisamente acudir a la sapiencia filosófica de todos los tiempos, aquella que puede colaborar hoy en la salvaguarda del futuro del hombre, movilizando esas fuerzas reales en las que cabe fundar la esperanza, y que son, justamente, las fuerzas de la philia. 